\title{
Modeling of Integration Processes in the Business Structures
}

\author{
Ragulina Y. V. ${ }^{1}$, Stroiteleva E. V. ${ }^{2} \&$ Miller A. I. ${ }^{3}$ \\ ${ }^{1}$ Doctor of economics, Professor, Moscow Academy of Entrepreneurship under the Government of Moscow, \\ Moscow, Russia \\ ${ }^{2}$ Assistant professor of economics, Department of Taxes Ulianov, Altai State University, Russia \\ ${ }^{3}$ Doctor of economics, assistant professor of socio-economic processes ANOO IN, Altai Academy of Economics \\ and Law, Russia \\ Correspondence: Ragulina Y. V., Doctor of economics, Professor, Moscow Academy of Entrepreneurship under \\ the Government of Moscow, Moscow, Russia. E-mail: julra@list.ru
}

Received: October 24, 2014

Accepted: December 8, 2014 Online Published: January 11, 2015

doi:10.5539/mas.v9n3p145

URL: http://dx.doi.org/10.5539/mas.v9n3p145

\begin{abstract}
The article suggests the methodological approaches to the problems of corporate actions harmonization and optimization, as well as the mathematical and computer modeling of supporting information flows, a systematic analysis of mathematical and computer modeling, which is connected with many decision-making centers, was conducted. The main problems of those centers are the propagation of constraints, coordination of decisions, implementation of the principle of cooperation and ensuring a fair balance between the interests of its participants. The main purpose - to ensure that the simulation model will not lose its adequacy and realistically reflect the ongoing production processes, that shall be mandatory confirm with the coincidence of appropriate practical data and data, which will be obtained during the modeling in the business structures.
\end{abstract}

Keywords: modeling, integration processes, business structures, corporate management, balance of interests

\section{Introduction}

The main problem of this trend of integration processes is the substantiation of methodological approaches to the problems of corporate decisions harmonization and optimization, and the mathematical and computer modeling of supporting information flows. In practice, the listed complex of problems arises during the design process of corporate information systems, which are currently increasingly used in the modern integrated business structures. However, their use is more often limited by the reference, and control functions, a single information union space formation and maintenance of an agreed schedule of activities of the corporate structure and separate business structures (Granberg, 2001; Kasperk, 1997).

\section{Methods}

The methodological approaches to organizing an effective management system lie within the theory of corporate management (Ansoff, 2001; Grafova, 2006; Oskorbin, 1989). The basis of systems efficiency are the following principles:

- maximum autonomy of the production activities of individual business structures;

- decomposition of processes and personal responsibility when making the managerial decisions;

- evaluation of the contribution of each party in the end results of corporation;

- fair reward of staff based on the actual activity results.

A complex (large) management system with many decision-making centers acts as the object of the system analysis and mathematical and computational modeling. Its main problems are the coordination of constraints, coordination of decisions, the implementation of the principle of cooperation and ensuring a fair balance between the interests of its parties [2;9;17].

The considering area of scientific researches is within the theory of active systems, hierarchical games and system compromise. In contrast to those areas of study the author considers the decision-making processes, in which the initial uncertainty is partially and fully eliminated at their implementation. Moreover, it is assumed that the estimates of corporate decisions, following their implementation, are made by the end results with 
complete certainty. Thus, we consider the production and management staff of business processes of the integrated business structure by the bearer of both types: not only as a "pure" Executors, but also as the active elements, which are able to participate in the adjustment of planned decisions on their business processes and to initiate the adjustment of decisions on the conjugate business processes. Such an approach to the management organization essentially expands the opportunities of activation of integration processes in business structures (Khorev and et al., 2004; Pine and Gilmore, 2005).

The mathematical modeling of those processes allows you to formalize the effects of interaction between the management union company (center) and separate business structures, to highlight the regularity self-organization in the hierarchical systems for the study, logically clearly to set tasks of stimulation and responsibilities of staff, which are adequate to the real corporate management systems. The given class of hierarchical systems - let us call them the hierarchical management systems with the restorable uncertainties - is developed on the basis of the mathematical model of decision-making processes, which is known as a corrective optimization model (Maksyutova, 2005; Bogoviz et al., 2013).

After the completion of corporate decisions implementation processes the restorable uncertainties allows you to conduct the "debriefing" that serves as the management enhancing effect for the integration process. In our case, the integration mechanism is based on the idea of active systems and envisages the involvement of creative potential of managers and specialists of the corporate structure, which is better-informed in the implementation process of decisions and is able to adjust the decisions in the interests of the overall system when properly stimulated. Thus, the integrated management system with the restorable uncertainties differs greatly from the classical objects of economic and mathematical modeling as the object for optimization (Vukovich \& Miller, 2013).

Moreover, in simple cases, the study of integrated structures can be carried out without using of complicated probabilistic and statistical methods and models of uncertain factors $[4 ; 10 ; 11]$.

1. We further shall consider the mathematical description of the two-level static hierarchical control system for the integrated business structure that comes down on the hierarchical game of $\mathrm{n}+1$ persons, determined by the following parameters: You set a common set of participants for the integrated union $I=\{0,1, \ldots, n\}$ and a set of business structures for the enterprises of the lower $I_{n}=\{1, \ldots, n\}$ and the upper $I_{0}=\{0\}$ levels. The Centre has the right to the first move, i.e. selects and announces his strategy to the elements of the lower level.

2. You shall determine the sets of admissible strategies for business structures $x_{i} \in X_{i}, i \in I$.

3. On the sets of $X_{0} \times X$, где $X=\prod_{i=1}^{n} X_{i}$, you determine the criteria and functions of payoff $F_{i}$ for each party of the integrated business structure:

$$
\begin{aligned}
& F_{0}\left(x_{0}, x\right) \rightarrow \max _{x_{0} \in X_{0}}, \\
& F_{i}\left(x_{i}, x\right) \rightarrow \max _{x_{i} \in X_{i}}, i \in I_{n} .
\end{aligned}
$$

4. For each business structure of the lower level you set the rules of behavior, which allow the center to evaluate the set of rational answers of players:

- desire to maximize (not worsening) the payoff function in their decisions;

- cautiousness - the commitment to the selection on the basis of guaranteed result under the incomplete information;

- desire to achieve an equilibrium situation or set of situations, Pareto optimal.

5. The mutual awareness of all the players about each other corresponds to the order of moves and determines the structure of the set of strategies $X_{i}^{\prime}$ of each player.

As a result of the corporate decisions formalization the economic and mathematical model was constructed. That model represents a hierarchical game from the mathematical point of view.

Current the study of hierarchical games is, generally. carried out in the following assumptions.

Rule 1.1. The center makes the first move, by selecting and informing the management of each business structure (a player of the lower level) the value of $x_{0} \in X_{0}\left(X_{0}=X_{0}^{\prime}\right)$ from the set of $I_{n} \mathrm{t}$

Rule 1.2. The player of the lower level, after he received the information about $x_{0} \in X_{0}$, aims to maximize its 
target function.

Rule 1.3. Knowing such a behavior rule, the center selects an element $x_{0} \in X_{0}$, which provides him the achievement of maximum guaranteed result.

For the "fan" integrated business structure, when the interests of the players $I_{n}$ are described by the payoff functions $F_{i}\left(x_{0}, x\right), i \in I_{n}$, it's proved that for the center the formulated decision of game is equivalent to the decision of two-person game, where one of the players is the center, and the second one - is the population of all business structures, i.e. an integrated player with such payoff function as $F\left(x_{0}, x\right)=\sum_{i \in I_{n}} F_{i}\left(x_{0}, x_{i}\right)$.

It should be noted that many of the organizational and economic mechanisms of functioning of organizational systems use this method of corporate decisions coordination. According to this principle the staff motivation is carried out by the end results. Such a functioning mechanism is used in the relations between the Tax Service of Russia and the taxpayers. There are also other examples. Let us call the given mechanism of corporate decisions coordination as M-1.

The second functioning mechanism of the integrated business structures is considered when the center has the information on the choice of their decisions by the subordinates. Let's denote the set of such choices as $X_{0}$.

Analogically, we provide a set of rules of corporate decision-making structure (M-2).

Rule 2.1. The Centre expects to receive the information (and it get it) on the choice of $x_{i} \in X_{i}, i \in I_{n}$.

Rule 2.2. The Centre makes the first move and tells each player of the lower level the appropriate strategy, as a function of $\phi_{i}^{0}$, defined on the set of choices of each player.

Rule 2.3. The player of the lower level, after he received information on the strategy $\phi_{i}^{0}$, aims to maximize its payoff function by the appropriate choice $x_{i} \in X_{i}, i \in I_{n}$.

Rule 2.4. In the formulated conditions the center seeks to obtain the maximum guaranteed result.

\section{Result}

As a result, the extensions of the center's strategies class, which correspond to an arbitrary order of transmission of information on their activities by the elements of the lower level, established by the center, may increase the expected payoff to the center due to increasing the number of options to build the organizational structure - the establishment of order of moves and the appropriate awareness.

The theory of hierarchical games provides a complete description of the corporate decision-making procedures (mechanisms) in this class of systems. It should be noted that the found optimal parameters of the functioning mechanism of integrated business structures (especially $\mathrm{M}-2$ ) are effective at the integration processes organization $[1 ; 7 ; 14]$.

Philosophically speaking the new ways of increasing the effectiveness of organizational and economic mechanisms are developed. The coordination of decisions is achieved by the delegation of authority to the lower levels of the hierarchy by the center therein. This technique, along with the controlled expansion of awareness of the center and business structures, is able to significantly improve the performance of the integrated business structures. That class of economic and mathematical models is called the system compromise models. However, in the development of applied mathematical models of the corporate decision-making systems a problem of the detailed process study of information exchange between the system elements occurs, with respect to a wide class of hierarchical systems (Ansoff, 2001; Stroiteleva, 2014).

The system compromise models take into account the strategies of information exchange and coordination of decisions arising from the interaction of parties to conflicts.

The basis of compromises' study in the hierarchical mutual relations of parties is a Two-level mathematical model.

The top-level party - center task is:

$$
\begin{aligned}
& F_{0}\left(x_{0}, x\right) \rightarrow \max _{x_{0}, x}, \\
& x_{0} \in X_{0}, \\
& x \in X .
\end{aligned}
$$

The lower level task (by the example of one of the parties - subsystem) is: 


$$
\begin{aligned}
& F_{1}\left(x_{0}, x\right) \rightarrow \max _{x}, \\
& x \in X .
\end{aligned}
$$

Here, $x_{0}-$ is a choice of the upper party (center). Namely the right to choose $x_{0}$ determines the hierarchy between the Centre and the parties of the lower level; $x$ - is a choice, which is jointly controlled by the parties in various hierarchy levels; $X_{0}, X$ - multiple choices of variables $x_{0}, x$, respectively.

The corporate decisions of scheme of system compromise can be reduced to the study of cases of inequality between the parties and the subsequent analysis of the two types of systems centralization: with "hard" and "soft" centralization. After delegating the authority and fixing the structure of information exchange between the center and the business structures of the lower level the search for corporate decisions is carried out using the mechanisms $\mathrm{M}-1$ and M-2. Thus, the mathematical models of system compromise do not lead to the new rules of interaction between the center and agents, however, at the design stage the additional integration functions, which improve the efficiency of corporate decisions, are implemented.

Let's imagine the results of a detailed analysis of structural variants of informed exchange in making the cooperative decisions, including when delegating of its authorities by the center. Within the mathematical models of system compromise such terms as the information transmission, awareness level of elements, asymmetry of awareness, information value, conditions of interest in the information transmission, and etc. are formalized. It should be noted that during the all of the studies within the system compromise the asymmetrically informed elements form their decision making problems "naturally". (Stroiteleva, 2012; Kaplan \& Norton, 2001; Eickhof \& Kreikenbaum, 1998).

(1) Let us consider the problem of centralization, decentralization and self-organization in the corporate managerial decision-making systems. Currently, such terms as centralization, decentralization and self-organization are stressed. They are related to the processes of decision making and implementation and largely studied on a qualitative level. However, in the literature the considerably less attention is given to the formalization of management processes and integrated study of the properties of controlled systems with different degrees of centralization, decentralization and self-organization. The considered herein model of corrective optimization and based on it management mechanism can be used for the aforementioned purposes. At the initial stage the study of complete corporate decision-making systems can be restricted by the study of management systems of centralization and self-organization, because the decentralization, in a first approximation, can be considered as "help" for the centralization. It is shown that the delegation of authority requires the appropriate management and stimulating mechanisms. Decentralization may be combined with self-organization, if the center controls and stimulates the decentralized part of its system only with the end results $[13 ; 14 ; 19]$.

Thus, the effect of self-organization in making and implementation of corporate decisions manifests itself in its pure form only when the center does not know and cannot know the terms to control the relevant part of the production system. This part of the system is not formalizable and can't be observed for it in the data and control spaces of decision making and implementation.

It should be noted that the self-organization processes arise also in the purely executive structures. The implementation of centralized decisions and decisions in systems of centralization, decentralization and self-organization assumes some actions of the Executor for the detailed elaboration of decisions, collection of baseline data for their implementation and real time actions. However, if the execution of decisions is carried out without their correction, in the general case the Executors have no need to attract the information about the system purpose as a whole (Bogoviz et al., 2013; Myrdal, 1957).

The considered aspects of self-organization require the additional studies in response to a number of factors, such as, "Japanese strike method" through the "work on the regulations". To evaluate the effects of self-organization you shall separately consider the Executors' work on the implementation of decisions as a routine and Executors' work on the decisions correction as a pure self-activity. Otherwise, any activity on the decisions execution may be mistakenly evaluated as the activity of creative (innovative) Executors.

Considering the center's functions it should be noted that in the centralization and self-organizing systems the center needs its own information for managing the Executor, otherwise the system becomes unmanageable. The value of the correction optimization model and its different variants, including the dynamic, is the possibility of designing the information processes and mechanisms of centralized management in their harmonious combination with the self-organization processes. This way essentially expands the integration level in the substantiation of corporate decisions. 
(2) The substantiation of planned decisions at the medium-term and annual planning acts as one of the most important functions of corporate management, which essentially determines the effectiveness of the integration processes' manifestations. At present the mechanisms of substantiation and implementation of planned decisions in corporations are designed hierarchically, at that the leading role remains over the decisions of the management union company. With such a mechanism the maximum flexibility in managing the productive resources is achieved. The peculiarity of the planning mechanisms' integrative component is that a synergistic effect is the highest, when there is a sufficient awareness level of the center. The disadvantage of such mechanisms is not fully awareness of the center at the time of planned decisions substantiation and the delay of their correction upon changing the external and internal environment of functioning for the integrated business structure. In the management systems with restorable uncertainty such disadvantages are partially removed by attracting the creative abilities of the production and managerial staff (Ansoff, 2001; Stroiteleva, 2012; Ragulina \& Zavalko, 2013).

The planned decisions hereinafter is the substantiation of nomenclature and production volume of business structures, provided by the local resources, resources placed at the disposal of the management union company and satisfying the terms of demand for the commodity markets. The term "optimal planned decisions" are referred to those decisions, which are admissible and ensure the maximum system (synergistic) effects. Currently, the total operating profit of the integrated business structures, calculated by the actual values of financial flows or by their discounted analogues, acts more often as such an indicator $[14 ; 16 ; 20]$.

(3) The substantiation systems for the planned decisions, which are built on a hierarchical type and projected considering the use of the creative potential of staff, are becoming more widely used in the corporate structures. The corporate decision-making systems, which are built on the hierarchical principle, are considered as the multi-level systems that are characterized by the presence of multiple decision making centers, a part of which is involved in the management on the principles of self-organization. The general approach to study the given class of systems consists of organizing the decentralized management or decentralized decision making. It is assumed that the system under consideration has a global goal, responsibility for the achievement of which, within the available means, is entrusted to the top-level element - the Center. The simplest structures are: a two-level structure that has two decision-making centers, a fan hierarchical system and a system with horizontal connections.

In the hierarchical systems a set of rules of interaction between the parties of the system lies at the core of all the ways for the decentralized decision-making, including the regulations of information transmission and exchange, i.e. the functioning mechanism of production systems. When substantiating the planning decisions, we develop a "soft" way of central management, the integration of which is due the use of basic M -1 and M-2 principles of decisions coordinating. A brief explanation of those principles as applied to the problem of the planning decisions substantiation and organization of their implementation processes $[5 ; 12 ; 15]$.

According to modern concepts, the functioning mechanism is: a system, organization that determines the order of any kind of activities. In integration processes modeling the given term is a key one and requires a detailed analysis. We define the decision-making mechanism (and their stabilization) as an aggregate of the following organizational management procedures:

- optimal composition determination of business structures in the substantiation of groups of planned decisions;

- description of the interests and abilities of each business structure as a whole;

- full description of the information hypotheses and awareness levels of elements in the substantiation system for the planned decisions;

- $\quad$ setting of regulations for the information transfer and prohibition of information distortion;;

- determination of the principal managerial characteristics for the corporate decision-making centers (awareness level, free choice of actions, rationality, sensitivity to the search for the optimum) and their vision;

- determination of objectivity and subjectivity level through the functioning mechanism, in terms of their implementation in practice (complete classification of game models and the choice of appropriate model).

Let us consider the mechanisms of production systems (companies, corporations) functioning - it's a corporate mechanisms, given that any complex production system implements the principle of corporate management. In such a system the role of the Center acts the company's owners. The management system is built on the hierarchical principle, like a 3 level system: 
- company's owners (their interests are represented by the Board of External Directors);

- Executive management (General Manager and his assistants);

- $\quad$ mid-level Managers of structural subdivisions.

We present one of the variants of the model representation for the regulations and orders for the functioning of parties of the complex decision-making process in the integrated business structures with restorable uncertainties.

Usually, the integrated system $S$ is described by the interrelated group of variables of four types

$$
s=\langle x, v, y, w\rangle,
$$

where $x$-are the variables characterizing the material, information and financial flows in the inlet,

$y$ - are the same groups of variables in the system output,

$v$ - decisions (control), by changing which the active elements of the center decision-making provide the achievement of those or other purposes;

$w$ - is a vector of parameters (terms, perturbation), which values cannot be changed by any of the decision-making centers in the system.

Let us denote $S^{o}$ - is a set of admissible states, at which the objective (technical, technological) constraints are executed, and $S^{M}$-is a set of admissible states at the existing management mechanism and game rules specified in the system. Then the system state $S$ shall be considered coordinated, if at the same time the requirements of $s \in S^{o}$ and $s \in S^{M}$ are met.

The given definition of coordinated decisions in the integrated system and its formalization is constructive, not contradicting the existing concepts and allows you to introduce into consideration the situation observed in practice during the decisions coordinating (Table 1):

- formation of ideas among all the decision-making centers in the integrated business structure about sets of $S^{o}$ and $S^{M}$;

- $\quad$ objectivity technical control of sets of $S^{o}$;

- legal and corporate compliance management of sets of $S^{M}$ with law in conducting of all the decision-making centers;

- organization of information processes to ensure the unity of all ideas of decision-making centers about the technical technological capabilities (sets of $S^{\circ}$ ). legal frameworks, economic interests and arrangements $\left(\right.$ sets of $S^{M}$ );

- $\quad$ extension of technical capabilities (sets of $S^{\circ}$ ) and changes in the rules and regulations of management mechanism (sets of $S^{M}$ ) in case of their contradictions and / or low efficiency of decisions;

- decision coordinating, i.e. the search for such a system state $S^{o}$, that satisfies the evaluation of all active parties of the considered (all the decision-making centers) system for the terms of sets of $S^{O}$ and $S^{M}$.

Table 1. Management functions in decisions coordination in large systems

\begin{tabular}{|c|c|}
\hline Management functions & Content \\
\hline $\begin{array}{l}\text { 1. Formation of representations of all DMPs } \\
\text { about "their" sets of } S^{O} \text { and } S^{M} \text {. }\end{array}$ & $\begin{array}{l}\text { 1. It clarifies by all decision-making centers of the set of } \\
S^{O} \text { and } S^{M} \text { for the specified mechanism and state } S \text {. }\end{array}$ \\
\hline $\begin{array}{l}\text { 2. Evaluation of technical and technological } \\
\text { capabilities. }\end{array}$ & $\begin{array}{l}\text { 2. Each business structure evaluates the capabilities for the } \\
\text { production of products and resource maintenance. }\end{array}$ \\
\hline $\begin{array}{l}\text { 3. Assessment of compliance of mechanism's } \\
\text { parameters with the norms of law and existing } \\
\text { Contracts. }\end{array}$ & $\begin{array}{l}\text { 3. All the parties of the union carry out analysis of the } \\
\text { compliance of its requirements and verify the feasibility of } \\
\text { inclusion } S^{M} \text {. }\end{array}$ \\
\hline $\begin{array}{l}\text { 4. Coordination of representations of all the } \\
\text { decision-making centers about the sets of } S^{o} \\
\text { and } S^{M} \text {. }\end{array}$ & $\begin{array}{l}\text { 4. In the case, when the set of } S^{O} \text { and } S^{M} \text { are not } \\
\text { described equally by all the decision-making centers, this } \\
\text { contradiction shall be eliminated in the system. }\end{array}$ \\
\hline 5. Expansion of sets of $S^{O}$ and $S^{M}$. & 5. The control system provides a mechanism for the \\
\hline
\end{tabular}


development, expansion of the nomenclature and production capabilities (for the sets of $S^{o}$ and $S^{M}$.)

6. Implementation of the conciliation process of decisions, assessment of admissibility.
6 . The integration process of information exchange for the system elements, resulting in the adjustment of $S^{o}$, so

that the inclusion of $S^{o}$ and $S^{c} \in S^{M}$ was performed with the specified level of admissibility.

Let us consider further the term of optimal decisions (state $S^{*}$ ), which operates in the case when in the integrated business structure a set of coordinated decisions can be realized. Formally, to optimize the decisions you must set the target function $F(s)$, defined for all coordinated decisions.

In the complex organizational systems the main difficulty in decisions optimizing is in the formalization of sets of $S^{o}, S^{M}$ and the function $F(s)$, which is usually not possible to implement to the end. Therefore, the process of optimization and coordination of decisions cannot be done in a single stage. In real time you need to implement a rather complex sequence of stages of decisions correcting with the simultaneous revision of "active areas" of sets $S^{o}, S^{M}$ and the function $F(s)$.

The above procedures have been repeatedly discussed within the theory, methods of decision-making and algorithms of block programming. It should be noted that in the real interaction between the decision-making centers it's impossible to implement the formal procedures of searching for the harmonized and optimal decisions even in approximate form, therefore, the formal methods can be used to obtain the estimate plans and their results. Having said that, we can distinguish four stages of the decisions harmonization and optimization:

1. Statement of the problem at optimization and harmonization of decisions, in which the elements of the problem have the conjectural (taking into account the initial information) nature. In general terms, this stage can be designated as the searching problem solution $S^{*}$ from the following condition:

$$
F\left(s^{*}\right)=\max _{s \in S^{O} \cap S^{M}} F(s),
$$

where we assume that the sets of $S^{o}, S^{M}$ and function $F(s)$ are unknown, but may be recovered (in their active parts) during the multi-stage procedures for harmonizing the decisions optimization.

2. Process start-up stage to find the optimal decisions $s$.

At this stage, by means of serial, parallel pendulum interaction of all lower decision-making centers and the central element (the center) during the coordination and optimization of decisions the necessary data are collected, typically, on the heuristic procedures to start searching for the decisions under the regulated algorithm.

3. Stage of system data accumulation.

At this stage, similar to item 2 the counter information exchanges between the center and all the decision-making centers are carried out, the purpose of which is the accumulation of data to clarify the formulation and solution of the problem (3.2) with the required accuracy. There are the formal criteria of completeness and accuracy of solution, which allow you to interrupt this process for all or some the decision-making centers. It should be noted that when you implement the items 2 and 3 the possibility of the decision coordinating and the ability to perform the functions are revealed.

4. Stage of searching for a decisions and its implementation.

At the stage 4 you can solve the problem (2) to find the optimal system state $S^{*}$ and the procedure for its responsible coordination considering the permissible error is carried out.

Let us consider further an extremely important management function in the integrated business structure - the function of decisions coordinating and the appropriate coordinating element of the system (management Company), which executes this function. While continuing the analysis of conceptual apparatus we give you (see Fig. 2) the functional structure of management in the systems with independent decision-making elements.

The figure shows the coordination function, which is more general and, in general, is not reduced to the harmonization and optimization. If the harmonization provides the admissibility of decisions, and the optimization - their optimality, then the coordination, as a control function, is reduced to the creation of such a mechanism of decisions autonomization for each decision-making center, under which all the decision-making 
centers independently choose the agreed and best decisions.

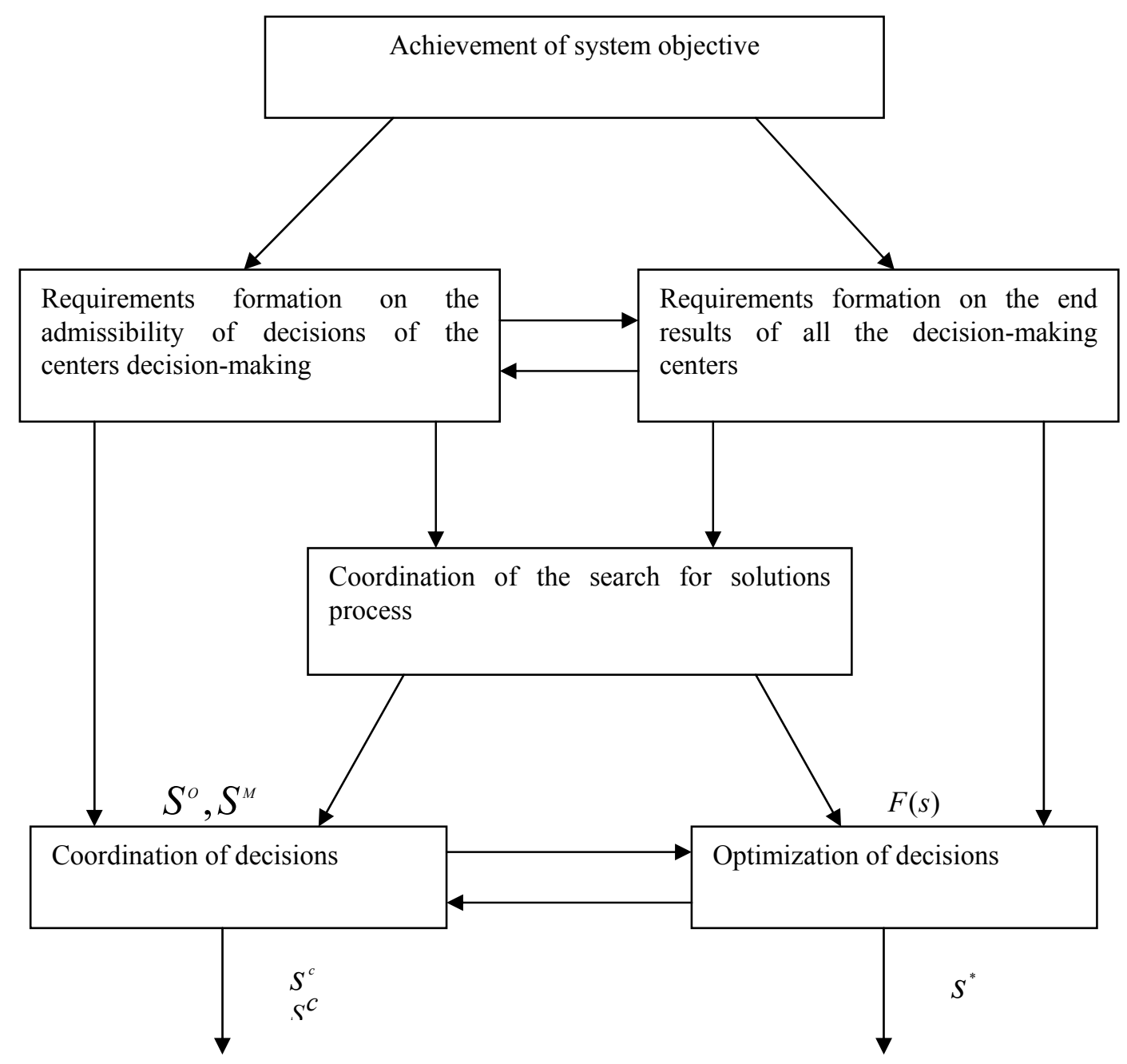

Согласованные решения

Оптимальные решения

Figure 2. Chart of planned decisions coordination and optimization in the corporate structures

Thus, the coordination answers the question of how, in what way you can achieve the optimal and coordinated decisions in the complex controlled systems by providing the managerial independence to the separate business structures and integrated business structures.

Within the proposed formalization, in the result of coordination, acting as a control function, the set of $S^{M}$ and the function $F(s)$ are formed for all the decision-making centers and the system as a whole, which are required to set the tasks of decisions coordination and optimization.

The validity of our analysis is confirmed by the conclusion of work (Bogoviz et al, 2013), according to which the special role of the coordination function, performed by Managing Authority in the two-level system, is reduced 
to solving of three problems:

1. The choice of the interaction principle between the parties - principle of coordination (coordination in the "large").

2. The choice of method of coordination, which can be implemented by the applying of additional constraints for the decisions of all the decision-making centers, purposes correcting of some of them, or the combinations thereof ("coordination in the small").

3. The choice of method for solving the problem of coordination, i.e. the method for implementation of the accepted method of coordination so that the interaction between the parties is concerted and optimal.

As we can see, the problem of the item 3 - decisions of the coordinating authority - is directly related to the functions of coordination and optimization, and this explains the close relationship of such terms as "coordination", "harmonization", and "optimization". Nevertheless, the performed analysis, in our opinion, clearly delineates the given terms and tasks, which you shall do to implement each of the functions. Moreover, we can explain the fact that the given terms are weakly separated in practice. The function of coordination or "clean governance" is inherent in any management systems, such as organizational and production, which contain two or more parties. However, the center, which, as a rule, makes up the coordination functions, simultaneously make decisions on the use of system-wide resources and takes over the choice of the part of operating influences, and thereby "helps" the subdivisions. In these terms the center and the environment do not share the named functions in practice. The systems analysis of the management tasks requires the specified separation, because the setting for and methods for solving the coordination problems and problems of selection of "own" variables is different. Then we methodically distinguish the coordination function, without forgetting about the second component of decisions of the center.

Let's consider the features of coordination of activities for the business structures and corporate structures in the planned and market economies. If the administrative coordination mechanism is implemented in the organizational system and, if the task of the substantiation of planned decisions (optimization) comes to the forefront, and any planned decision is easy coordinated, due to the rigidity of administrative management, then it means we are dealing with the Planned Economies.

From the standpoint of formal business structure controllability there is no alternative to the mechanism of the planned economy at the intrafirm-level. By reducing the role of the active elements of the economy to the performing activities, the coordinating authority receives the clear criteria of decisions coordinating. In this case, however, the issues of the decisions optimality recede into the second (rear) plan. The subsystems of the planned economy - business structure - due to the high fines and poor motivation are not interested in the objective information support of decisions: they hide their reserves and production capabilities.

If within the same system the effective initiative decisions (decision from the bottom) are not supported from the top, their acceptance and coordination are hardly possible.

The modeling of executors' economic behavior within the stimulating environments has been viewed in the preprint of N.M. Oskorbin and A.I. Miller. The work suggests the basic model of the Executor's stimulating, which takes into account his interests $f_{2}\left(x_{1}, x_{2}\right)$ and interests of the Center $f_{1}\left(x_{1}, x_{2}\right)$ :

$$
f_{1}\left(x_{1}, x_{2}\right)=c \cdot x_{2}-x_{1} ; \quad f_{2}\left(x_{1}, x_{2}\right)=x_{1}-b \cdot \varphi\left(x_{2}\right),
$$

where $x_{1}$-is the premium (bonus) amount paid by the center to the Executor $\left(x_{1} \geq 0\right) ; x_{2}-$ is the activity level of the Executor, i.e. the volume of production for the planned period, limited above by the $\Delta-$ is a marginal level $\left(x_{2} \in[0, \Delta]\right) ; \phi\left(x_{2}\right)$ - is a function of additional costs of the Executor that satisfies the following terms: $\phi(0)=0 ; \quad \phi^{\prime} \geq 0 ; \quad \phi^{\prime \prime} \geq 0 ; \quad C$ - profit from the sale of a product unit.

We have studied the decisions of the game, in cases where the center has the first move (mechanisms M-1, M-2) of both in the conditions of certainty and when he knows only the estimates: $\Delta \geq \Delta^{d}$.

The general principles for managing the Executors' activities in the social and economic systems are studied; the new variants of stimulating models are suggested.

Let us consider the problems of the practical application of executors stimulating models and the methodological approaches to their structural and parametric identification in adjusting and performing the planned tasks by the executors. The structure identification provides for the allocation of the interconnected decision-making models systems, and parametric identification includes the methods to substantiate the kind of particular models and to determine their numerical characteristics. 
The structural identification of the staff stimulating models we will conduct using the decomposition approach in accordance with the general formalization of the optimization process for the planned decisions. Mathematically, concretize the state $s$ at the substantiation of planned decisions of business structures (in this case the difference is not essential) as follows: $s=(z, w)$. In this case, the task of choosing the planned decisions (2) can be written in following general statement:

$$
\Phi(z, w) \rightarrow \max _{z \in Z(w)}
$$

where $\Phi(z, w)$ - is the target function of the system, dependent on the decisions made by all the active elements (management units at the system-wide and production technology level);

$w-$ is the system vector of parameters (external and internal disturbances);

$Z(w)-$ is the set of admissible planned decisions.

In the hierarchy of corporate decision-making process the planning subsystem stands out; under conditions of uncertainty with respect to perturbations, it retrieves a preliminary decision of $z^{\circ}$ :

$$
G\left(z^{\circ}\right)=\max _{z \in Z^{o}} G(z), \text { где } Z^{o}=\bigcap_{w \in W} Z(w) ; \quad G(z)=\min _{w \in W} \Phi(z, w)
$$

By assuming that the Executor knows exactly the value of the vector $w$, we can evaluate its possibilities to increase the efficiency of his business process. Using the notation of the mathematical model, we have as follows:

$$
\Delta\left(z^{\circ}, w\right)=\max _{z \in Z(w)}\left[\Phi(z, w)-\Phi\left(z^{o}, w\right)\right] \geq 0 .
$$

During the implementation of plan $z^{0}$ the Executor may be interested in the choice of corrective decision $z^{*}\left(z^{o}, w\right)$ increasing the efficiency of the business system, if he expects the reward, which we will define as a share $x_{1} \in[0,1]$ of the result of $x_{2} \in\left[0, \Delta\left(z^{0}, w\right)\right]$.

The managerial aspect of recorded expressions consists in dividing the general synergistic effect of the integrated process for the optimization of planned decisions between the planning center and executors, who shall correct the planned decisions when implementing the tasks of the center. The conducted decomposition of integrated process for the substantiation of optimal planned decisions serves two functions:

- optimal integration of the Executor in the process of correcting the planned decisions;

- determination of the share of bonus for the Executor, including the executive management, in the end result.

Using these methods, we can show that the introduced decisions of $z^{0}, x_{1}^{*}, x_{2}^{*}, z^{*}\left(z^{0}, w\right)$ are determined by the expressions (5), (6) and the following game-theoretic model.

The task of stimulating Center:

$$
f_{1}\left(x_{1}, x_{2}\right)=\left(1-x_{1}\right) \cdot x_{2} \rightarrow \max _{0 \leq x_{1} \leq 1}
$$

The task of the Executor:

Production task of the Executor:

$$
f_{2}\left(x_{1}, x_{2}\right)=x_{1} \cdot x_{2}-\varphi\left(x_{2}\right) \rightarrow \max _{0 \leq x_{2} \leq \Delta\left(z^{\circ}, w\right)} .
$$

$$
\left|x_{2}^{*}-\left(\Phi\left(z^{*}, w\right)-\Phi\left(z^{\circ}, w\right)\right)\right|=\min _{z \in Z(w)}\left|x_{2}^{*}-\left(\Phi(z, w)-\Phi\left(z^{\circ}, w\right)\right)\right| .
$$

In the expression (9) $x_{2}^{*}-$ is the aggregated decision of the Executor (level of his activity) in the game (7), (8).

It should be noted that at low potential of activity of the Executor or at a sharply increasing costs at stimulating the staff activity the use of the discussed mechanism may be not advisable. In this case, $x_{2}^{*}$ takes the zero solution in the game, and from it follows that $z^{*}$ can be chosen equal to the planned decision $z^{0}$, the implementation of which should be supported by the appropriate system of executing control.

In the integrated business structures the information and management aspects of the staff stimulating system are as follows. The Planning Centre, using its models and its level of abstraction, searches for the plan $z^{0}$, with the problem solution, which is considered in details previously. The stimulating center:

- firstly, evaluates the potential of staff activity; 
- secondly, finds the optimal level of rewards with the solution of the game in its information environment;

- thirdly, coordinates the activity level $x_{2}^{*}$ with the Executor.

The Executor shall fulfill and exceed the planned task within his information environment. It is controlled according to the agreed level of the end result.

The hierarchy of allocated stages of corporate decision-making in the management of integrated business structure is shown in Figure 2.

Planning subsystem

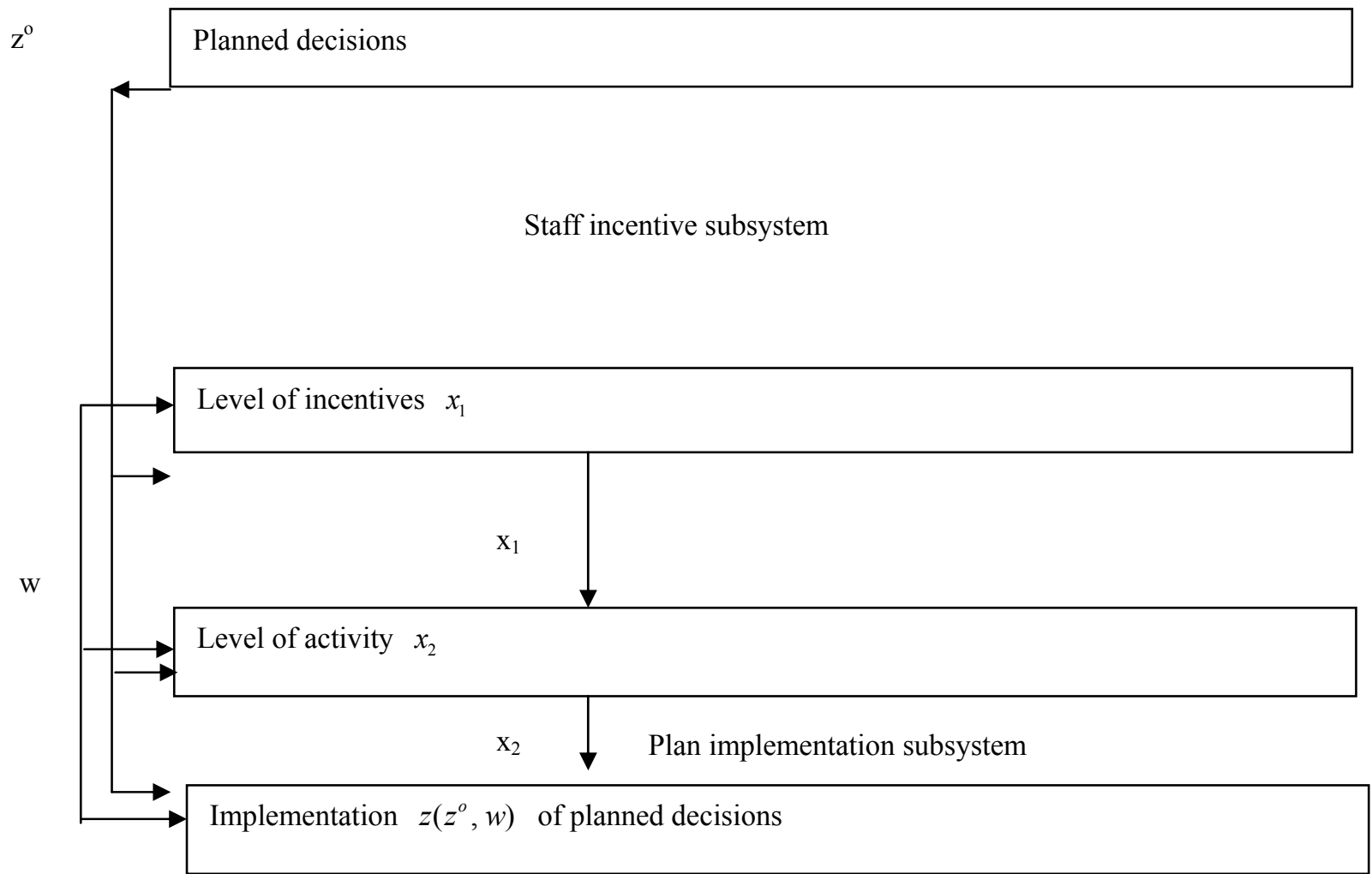

Figure 2. The hierarchy of integrated decision-making and planned decisions implementation processes in inducing the staff of the corporate structure

By remaining, generally, within the proposed decision-making structure, let's consider the options of particular problems statement and the methods of estimating the models parameters (5), (7)-(9), which can be implemented in terms of corporate structures.

We consider the problem of identifying the model parameters in the formulation to determine the strategies of remuneration staff. Suppose $x_{2}^{H}-$ is a performance rate, i.e. the volume executed by the average worker on the given labor market per operating hour. In terms of direct piece rate remuneration system the amount of remuneration $x_{1}$ in the model (4) is defined as follows: $x_{1}=p x_{2} / x_{2}^{H}$, where $p-$ is a wage rate, which is set by the employer (stimulating center). For the logarithmic function of labor costs we write the Executor's activity model as follows:

$$
f_{1}\left(p, x_{2}\right)=\frac{p \cdot x_{2}}{x_{2}^{H}}-\delta\left|\ln \left(1-\frac{x_{2}}{\Delta}\right)\right| \rightarrow \max _{0 \leq x_{2} \leq \Delta},
$$

where $\delta$ - is a function parameter of labor costs, which reflects not only the severity of labor, but also the degree of worker's attitude to the remuneration in terms of its value.

The last statement can be proved as follows. Let us consider the behavior model of the Executor as the 
two-criterial optimization problem with a linear convolution of criteria, the comparison of which conducts the Executor in his system of values. Hence, when identifying the parameter the given system of values will be reflected in the estimation of labor costs.

Now we can find the estimate of the parameter $\delta$ at the known $x_{2}^{H}$ in the model (10). Make use the solution of the problem to the maximum (8):

$$
x_{2}^{*}(p)=\max \left(0 ; \Delta-\frac{\delta \cdot x_{2}^{H}}{p}\right)
$$

To determine $\delta$ we should use the point $\left(P_{H}, x_{2}^{H}\right)$ found by the work quota methods. Taking into account (11) we can form the equation $x_{2}^{H}=\Delta-\frac{\delta \cdot x_{2}^{H}}{p_{H}}$. Whence it follows that:

$$
\delta=P_{H}\left(\frac{\Delta}{x_{2}^{H}}-1\right)
$$

Let us consider further a method of estimating $\Delta$ for the market average worker. We shall single out the workers of fixed profession and specialization on the investigated labor market and take as a hypothesis the statement about the relative stability of index $\alpha \in[0,1]$ the ratio $x_{2}^{H} / \Delta$ (for the Russian labor market and working professions you can offer the evaluation in the index of average labor intensity $\alpha$ on the level. Then the results of parameters identification for the model (11) can be written as follows:

$$
\delta=\frac{P_{H}(1-\alpha)}{\alpha} ; \quad \Delta=\frac{x_{2}^{H}}{\alpha}
$$

The model can be used to study the behavioral characteristics and individual workers. It should be noted that according to the tradition of labor economics the individual stimulation of workers is determined by the parameters of the market average worker, therefore that aspect of methodological approaches is not considered in stimulating the staff of integrated business structures.

The simulation modeling of managerial production business processes is fairly labor intensive. The majority of integrated environments orients the user to the representation of those processes and systems as a combination of some flows, whether the flows of raw materials, money, or other resources.

In this case we are dealing with a classical queuing system that gives an abstract, simplified representation of such real systems, where you can distinguish two main classes of objects: flows of requests (demands) for service and serving them objects, which are linked into the network. The simulation models of queuing systems are the discrete event models, since in their functioning a change in the state of such systems occurs at the discrete moments of time when such events as sampling of requests from the input queue for service, end of service, and etc. take place.

\section{Discussion}

The modern simulation modeling systems allow you to model a wide class of discrete-event systems using the visual flexible expandable blocks of both standard, which are in the relevant libraries, and additionally created by the developer.

The implementation of standard objects of such libraries is open for the user, and its functionality may be expanded as you like, up to creating of your own libraries. Many libraries in the modern systems of simulation modeling contain not only the traditional objects of queuing systems, but also the objects, which are typical for the production modeling: queues, delays, conveyors, resources, etc.

It should be noted that the simulation modeling consists of two big stages: a model creation and analysis of the constructed model in order to make the various management decisions (Brueckner, 2002).

Let us consider the stages of simulation modeling by the example of technological processes, where the collection of information on the object of modeling can be performed using the technical documentation.

During the simulation model construction it's necessary to allow some simplifications of the real system behavior to maintain its performance. In particular, with regard to:

- $\quad$ parts and components transportation within the production;

- $\quad$ staff performance;

- $\quad$ operating modes of a business structure, and etc. 
It is also necessary to highlight the circumstance that the price of consumed resources (metal, plastic, electricity) is very dynamic. When developing the model it is necessary to include an additional module, which takes into account the changes in prices of those kinds of resources and allows you to operatively calculate the possible extra costs of such changes.

Further on the basis of the information collected it's necessary to formulate the main technological problems, the solution of which is supposed to carry out by the model construction. In this list can be included the following possibilities:

- animation of electricity consumption by the production equipments in operating mode;

- $\quad$ animation of consumption of other material resources by the production equipments;

- evaluation of time of non-forced outages and breaks in the equipment operation, due to the technological process;

- $\quad$ animation of labor productivity of the worker and collective of production as a whole separately for any length of time;

- evaluation of production costs in the itemized section for any time intervals (or at specified options production volume).

These problems define the logic of the simulation model construction and allow forming the lists of its input and outputting parameters. It is necessary to take into account the fact that the detail of the model should be at a fairly high level. However, there will be a certain number of assumptions therein, without which the model construction can be highly time-consuming. All those aspects are important, but not decisive with respect to this type of production, since they do not affect the essence of technological process. In order to compensate for the lack of performance the allocation of a part of the model functions in a separate computer program can be used, apart from the usual enlargement of model details in such cases. In this case, the model accuracy improving is achieved, by the collection of statistical data, and the subsequent input of corrective parameters in the simulation model.

In order to simulate the selected production it's necessary to expand the functionality of a model created and to go beyond the discrete-event simulation, for example, to set a complex and non-trivial behavior of the model's objects using the Statecharts.

According to the object-oriented modeling methodology, first of all you should develop the so-called "class of machine", allowing you to simulate the operation of all types of equipment, involved in the production. Next, you shall enter a list of variables, input and output parameters for each type of equipment, involved in the production process.

\section{Conclusion}

Thus, the main purpose - is to ensure that the simulation model will not lose its adequacy and realistically reflect the ongoing production processes. It is necessary to confirm by the coincidence of respective practical data and data, which will be obtained during the production simulation of specific products. Further, it is necessary to make appropriate adjustments in the simulation model, and to correct any inaccuracies identified during the model launching for performance in various modes.

The simulation model can become accessible to a wide range of people in the case when the simulation results are in layman's terms presented in the form of graphs, figures, diagrams, which reflect the answers to the questions of specialists on this type of production. The analysis of model can be made by those specialists in order to substantiate the management, design, and technological decisions for the production business processes and the choice of strategic and current decisions at improving the management business processes.

\section{References}

Ansoff, I. (2001). Strategic Management: Translated from English (3rd ed.). Revised. and ext. Economics, Moscow, 385.

Bogoviz, A. V. (2013). Modeling the Labor Process One of the Tasks of Strengthening of Positive Trends in the Economic Growth of the Industrial Enterprises of the Region. World Applied Sciences Journal, 8(25), $1222-1225$.

Bogoviz, A. V. (2013). Regional Aspects of Labour Management. Middle East Journal of Scientific Research, $8(16), 1105-1108$.

Brueckner, J. K. (2002). Airport Congestion When Carriers Have market Power. The American Economic Review, 
92(5). http://dx.doi.org/10.1257/000282802762024548

Economics and development of the enterprise. Retrieved from www.kylbakov.ru/pagel 10/pagel 15/index.html

Eickhof, N., \& Kreikenbaum, D. (1998). The liberalization of markets for conducted energy. Economy and competition, 48(7-8).

Ghoshal, S., \& Bartlett, C. A. (2000). The Individualized Corporation: A Fundamentally New approach to Management [Text]. Random House Business Book, 4, 56-58.

Grafova, G. (2006). The rating estimation of the economic state of the enterprise. Entrepreneurship, 4, 89-102.

Granberg, A. S. (2001). Strategy of territorial social and economic development of Russia: from idea to implementation. Issues of Economics, 9, 9-15.

Kaplan, R. S., \& Norton, D. P. (2001). The Strategy-Focused Organization. Harvard Business School Press.

Kasperk, G. (1997). Deregulation and privatization of of the electricity sector in developing countries. Baden-Baden.

Khorev, A. I. (2004). Strategic management of the industrial business activities. VSTA, Voronezh, 180.

Maksyutova, A. A. (2005). Business Planning of Enterprise Development. Alfa-Press, Moscow, 288.

Myrdal, G. (1957). Economic Theory and Under-Developed Regions. L.

Oskorbin, N. M. (1989). Some Aspects of Optimization of Decision Support System. Volume of Abstracts International School: Seminar Optimization Methods and Their Applications. Baikal, 66-67.

Pine II, B. J., \& Gilmore, J. H. (2005). The experience economy. Work is theatre 92. UNCTAD, World Investment Report: Transnational Corporations and the Internationalization of R D, figure IV. 1.

Ragulina, J. V., \& Zavalko, N. A. (2013). Integration Processes in the Chain: Science, Higher Vocational Education and Production, as a Factor in the Increasing the Competitiveness of the Educational Institution. Middle East Journal of Scientific Research, 13(Socio-Economic Sciences and Humanities), 161-166.

Stroiteleva, E. V. (2014). The problems of strategic and targeted program planning in the regions. Bulletin of the University (State University of Management), 3, 75-79.

Stroiteleva, E. V. (2012). The problems in the strategic management of business structures in regions. Economics of Sustainable Development, 11, 208-210.

Vukovich, G. G., \& Miller, A. I. (2013). Modeling and selection of forecast modernization scenarios of regional highly integrated structures (by the example of industrial corporations in Altai Territory). Journal of Economic Integration, 3(60), 91-94.

\section{Copyrights}

Copyright for this article is retained by the author(s), with first publication rights granted to the journal.

This is an open-access article distributed under the terms and conditions of the Creative Commons Attribution license (http://creativecommons.org/licenses/by/3.0/). 